\title{
DIE MAKRO-GESPREKSTRATEGIE IN 1 KORINTIËRS 1-4
}

L.D. JACOBS

\section{Inleiding}

In die bestudering van die Nuwe-Testamentiese briefliteratuur is daar tot op datum nie genoeg aandag geskenk aan die kommunikatiewe aspek van die briewe ${ }^{1 /}$ as sodanig nie. Roberts raak hierdie probleem aan wanneer hy tereg beweer: "Paulus is in sy briewe nie besig om sy teologie sistematies te ontwikkel en van brief tot brief sy groeiende insigte uit te spel nie. Inteendeel: Vanuit ' $n$ bepaalde teologiese oortuiging is hy telkens besig om mense in hulle bepaalde situasie van raad te bedien of te vermaan of te onderrig." (Eie kursivering). ${ }^{2}$

'n Nuwe rigting in die taalkunde poog juis om hieraan aandag te skenk. Die basiese uitgangspunt van die teorie van taalhandelinge wat in 1962 deur ' $n$ reeks William James-lesings van J.L. Austin by Harvard van stapel gestuur is, ${ }^{3}$ ' is dat 'n spreker sekere handelinge uitvoer wanneer hy praat met die doel om 'n bepaalde reaksie by sy hoorder(s) teweeg te bring. Drie sentrale begrippe in die taalhandelingsteorie is die lokusie, d.i. die uiting van ' $n$ sin met ' $n$ bepaalde betekenis en verwysing, die iflokusie, d.i. die seggingskrag van die uiting wat aansluit by die intensie van die spreker (bv. 'n bevel, belofte, versoek, e.s.m.) en die perlokusie, d.i. die handeling waarmee die spreker ' $n$ bepaalde effek of reaksie by sy hoorder wil ontlok."

' $n$ Verdere belangrike komponent van die teorie is die bestudering van gesprekstrategieë, d.i. tegnieke wat die spreker aanwend, waarmee "'n taalhandeling sodanig gemodifiseer word dat die hoorder soveel as moontlik beïnvloed word". 5)

Die doel van hierdie artikel is dan om 'n oorkoepelende gesprekstrategie, genoem makrostrategie, te identifiseer in die teksgedeelte wat vir dié doel uitgekies is, naamlik 1 Korintiërs $1-4$.

\section{Die Nuwe-Testamentiese brief as gesprek}

Om die geskrewe teks in verband te bring met ' $n$ taalhandelingsbenadering moet die teks en daarom ook die Nuwe Testamentiese brief as 'n gesprek beskou word. 
Die brief slaag as gesprek wanneer die leser die boodskap wat tot hom gerig is, realiseer. Sodra hy hierdie boodskap realiseer, word hy die ontvanger daarvan, ' $\mathrm{n}$ gesprek vind plaas en taalhandelinge kom tot stand. Hierdie proses word deur Van Coller en Van Rensburg ${ }^{6)}$ skematies soos volg voorgestel:

Sender Boodskap Geadresseerde

$$
\leftarrow---- \text { : Ontvanger }
$$

Aangesien 1 Kor. 1-4'n besondere afgeronde eenheid binne die eerste Korintiërbrief vorm, kan die gedeelte vir ons doeleinde as praktiese voorbeeld van 'n lewendige gespreksituasie tussen Paulus en die gemeente van Korinte beskou word.

\section{Die term makro-gesprekstrategie}

In haar omskrywing van gesprekstrategieë onderskei Van der Riet tussen mikro- en makrostrategieë: ${ }^{71}$

'n Mikrostrategie bestaan uit een taalhandeling of ' $n$ modifikasie daarvan.

'n Makrostrategie daarenteen, bestaan uit 'n reeks taalhandelinge wat gerig is op 'n sekere reaksie by die hoorder.

' $n$ Goeie voorbeeld van so 'n makrostrategie word deur Van der Riet $^{8)}$ verskaf, waarin 'n student haar pa in 'n brief om geld vra:

"My geld is op.

Julle is mos lief vir my.

Moenie dat ek so swaar kry nie.

Boeke kos honderde rande.

Ek kan nie eers fliek toe gaan nie.

Stuur asseblief geld."

Die skryfster dring deur middel van 'n reeks mikrostrategieë aan op 'n sekere perlokusie (reaksie), naamlik dat haar vader geld aan haar sal stuur.

\section{Die makrostrategie in 1 Korintiërs $1-4$}

Verskeie skrywers ${ }^{9 /}$ is dit eens dat die twee Korintiërbriewe wat behoue ISSN 0257-8891 = SKRIF EN KERK Jrg 7(2) 1986 
gebly het, deel uitmaak van 'n veel omvattender kontak en korrespondensie tussen Paulus en die gemeente in Korinte. In 1 Kor. 5:9 verwys Paulus dan ook na 'n vorige brief waarin hy die Korintiërs vermaan het om nie met onsedelike mense om te gaan nie.

Vergelyk 5:9: "éngrapsa humîn teî epistoleî me sunanamígnusthai pornois". (In die vorige brief het ek aan julle geskryf om nie met mense om te gaan wat in onsedelikheid leef nie).

Paulus se bedoeling met hierdie "vorige brief", wat waarskynlik verlore geraak het, is deur die Korintiërs verkeerd geïnterpreteer. Hulle het verstaan dat hulle hulle heeltemal van alle onsedelike mense moes distansieer, iets wat in die kosmopolitiese hawestad Korinte uit die aard van die saak totaal onmoontlik sou wees. Wat Paulus wel bedoel het, was dat die gelowiges nie moes omgaan met mense wat vóórgee dat hulle gelowiges is, maar steeds onsedelik geleef het nie.

Wanneer Paulus dan in 5:11 sê: "nûn dè éngrapsa humîn ..." (Maar nou skryf ek aan julle ... - 1933-vertaling), kan ons aflei dat dit vir hom uiters belangrik is dat die gemeente in Korinte hom nie weer verkeerd moet verstaan nie.

Dit was egter nie die enigste probleem waarmee Paulus in Korinte te kampe gehad het nie. Dit blyk asof die Korintiërs dit moeilik gevind het om hulle affiniteit vir die seksuele - wat so 'n groot rol in die stad se vroeëre geskiedenis gespeel het - af te skud. ${ }^{10}$ ) Dit word goed geillustreer deur Paulus se woorde in 5:1 "hólos akoéetai en humîn porneia" ('n Mens hoor werklik van onsedelikheid onder julle).

Paulus waarsku ook teen die ernstige verdeeldheid in die gemeente, vergelyk 1:11: "edelothe gár moi peri humon ... hóti érides en humin eisin" (Omdat van Chloë se mense my vertel het dat daar onenigheid onder julle is).

Die probleem het blykbaar gesetel in wat Lategan "11 " 'n soort persoonlikheidskultus" noem, gekoppel aan die name van Apollos, Paulus, Séfas en Christus.

Wanneer hierdie en ander faktore in gedagte gehou word, lyk dit asof Paulus by die skrywe van 'n opvolgbrief (d.i. 1 Korintiërs) tussen twee makrostrategieë moes kies, naamlik om

of die Korintiërs te vermaan vanweë al die probleme en wanpraktyke in hulle midde;

of die Korintiërs te onderrig in die ware leer en lewe wat van hulle as gelowiges verwag word.

\subsection{Kor. 1-4 - 'n vermaningsgesprek?}

Uit die voorafgaande is dit duidelik dat die gemeente van Korinte geen 
modelgemeente was nie. Gevolglik sou 'n woord van vermaning of teregwysing van die kant van Paulus nie onvanpas of onredelik wees nie. Die vraag is egter of dit korrek is om 1 Kor. $1-4$ as 'n stuk teregwysing te lees en 'n makrotaalhandeling met die illokusie/seggingskrag "Ek verwyt julle ..." of "Ek wys julle tereg ..." te identifiseer.

Daar kan veral twee redes aangevoer word waarom die gesprek nie as ' $n$ vermaning gelees behoort te word nie. Die redes het te doen met:

die komplekse situasie in Korinte, en

die konteks waarbinne die taalhandelingswerkwoord paraka/o in die teks voorkom.

\subsubsection{Die situasie in Korinte}

Alhoewel hy waarskynlik meer as genoeg rede gehad het om sy lesers oor die kole te haal, is Paulus baie bewus van die besondere omstandighede in die jong gemeente:

Die Korintiërs het nog nie 'n baie hoë peil van geestelike volwassenheid bereik nie.

Vergelyk 3:1: "edunethen lalèsai humîn ... hos neppiois en Christó $i^{\prime \prime}$. (ek kon met julle ... praat ... soos met kindertjies in die geloof in Christus).

Tweedens het die jong Evangelie maar 'n opdraande stryd gevoer in die sedelik afvallige hawestad Korinte. Vergelyk Morris ${ }^{12)}$ oor Korinte:

"It was intellectually alert.

It was materially prosperous.

It was morally corrupt".

Derdens besef Paulus ook dat die Korintiërs bloot eg menslik opgetree het deur hulle op die gemeenteleiers te verlaat vir leiding en wysheid.

Vergelyk 3:4: "hótan gàr legeî tis; ego mén eimi Paúloe, héteros dé; ego Apollo, oek ánthropoi este?" (As een van julle sê: "Ek is vir Paulus," en 'n ander: "Ek is vir Apollos," is julle dan nie nog wêrelds (menslik - L.D.J.) nie?).

Talle vrae het boonop in die harte van die gelowiges in Korinte geleef, veral rondom praktiese sake soos huweliksaangeleenthede, 
die eet van afgodsoffers, die beoefening van geestelike gawes, die opstandingsleer, ens. Hierdie vrae het die gemeente in 'n brief persoonlik aan Paulus gerig.

Vergelyk 7:1: "peri dè hon engrápsate". (Ek kom nou by die dinge waaroor julle aan my geskryf het).

Paulus se lesers in Korinte het dus nog heelwat leiding nodig gehad rondom die daaglikse optrede van 'n Christen in ' $n$ oorwegend heidense stad. Daarom besef Paulus dat verwyte en skerp teregwysings die jong lidmate dalk net verder van die Evangelie af sal laat wegdryf.

\subsubsection{Die konteks van parakalo}

Taalhandelingswerkwoorde of performatiewe gee uitdrukking aan die //lokusie van die uiting, $\mathrm{nl}$. of dit 'n vraag is (vra), 'n belofte (belowe), 'n bevel (beveel), ens. Dit kom altyd voor in die teenwoordige tyd en in die formule "Ek - jou/julle: ...". Gemeet aan die kenmerkende eienskappe van taalhandelingswerkwoorde, kwalifiseer slegs een werkwoord in die teksgedeelte as eksplisiete performatief, naamlik parakalo. ${ }^{13}$

Vergelyk 1:10: "parakalo dê humás, adelfoi, dià toê onómatos toê kurioe hemón Jèsoê Christoê, hína tò autò légete pántes" (Ek doen 'n beroep op julle almal, broers, in die Naam van ons Here Jesus Christus, om eensgesind te wees), en 4:16 "parakalo oên humâs, mimetai moe gínesthe". (Daarom spoor ek julle aan: Volg my voorbeeld!)

Die Afrikaanse vertaling van 1933 het paraka/o deurgaans met die performatiefformule "Ek vermaan (julle)" vertaal. Ook by ander vertalings en kommentare op die Griekse Nuwe Testament is die gedagte van 'n sterk vermaning of verwytende teregwysing duidelik teenwoordig. Dit sou die leser daartoe kon lei om by hierdie gedeelte ' $n$ vermaning as oorkoepelende illokusie in te lees. ${ }^{14}$

Die meeste woordeboeke oor die Griekse Nuwe Testament laat in die betekenisvariante wat hulle aangee egter die klem val op vier aspekte, naamlik:

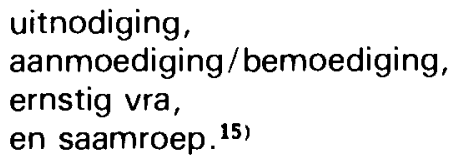

Die illokusie van die twee sinne waarbinne parakalo in die gedeelte voorkom (1:10 en 4:16), kan slegs in die gees van die hele gedeelte geïnterpreteer word. Wanneer dit gedoen word, is vermaan as 
ekwivalent vir parakalo te sterk.

Die betekenisekwivalent "ernstig vra", blyk dan die basis te wees waarop Paulus se ernstige versoek in 1:10 teruggaan, sodat die keuse wat die 1983-vertalers van die Afrikaanse Bybel gemaak het, naamlik "Ek doen 'n beroep op julle ...", inderdaad die korrekte is.

In 4:16 kom weer ' $n$ andersoortige taalhandeling aan die orde, wat waarskynlik eerder met die ekwivalent "aanmoedig" verbind moet word, sodat die 1983-vertaling van "Daarom spoor ek julle aan ..." die korrekte keuse blyk te wees.

Daar kan dus aanvaar word dat die aard van die gesprek en dus die makrostrategie nie hoofsaaklik vermanend, teregwysend of verwytend is nie.

Wat is dan die aard van die gesprek?

\subsection{Kor. 1-4 - 'n onderriggesprek?}

Die eerste vier hoofstukke van 1 Korintiërs kan as 'n tipiese herderlike onderiggesprek beskou word. Groenewald"16) beweer tereg: "Ten einde op al hierdie dinge in te gaan, en met die apostoliese gesag wat aan hom toevertrou is, voorligting te gee, skryf die apostel sy tweede brief aan die Korintiërs, d.i. die brief wat ons besit as 1 Korintiërs (eie kursivering).

Ter stawing hiervan kan daar veral twee bewyse aangevoer word, naamlik:

bewysplase in die teksgedeelte wat dui op 'n onderrigsituasie; en

erkende onderrigtegnieke wat deur Paulus in die gedeelte aangewend word.

\subsubsection{Bewysplase in die teks}

In die Griekse teks van 1 Korintiërs $1-4$ is daar talle voorbeelde van woorde en begrippe wat direk heenwys na 'n opvoedings- of onderrigsituasie, waaronder:

1:4: "kai páseî gnoseî" (en alle kennis).

2:2: "ti eidénai" lom oor niks anders te praat nie).

2:4: "ho logos moe" (die boodskap wat ek verkondig).

2:8: "hen oedeis éngnoken" (wat niemand geken het nie). 
2:13: "oek en didaktois ... lógois" (nie met geleerde woorde nie).

"sungkrînontes" (so verklaar ons).

2:16: "tîs gàr égno noên" (Wie ken die gedagtes?)

"hós sumbibásei autón" (Wie sal Hom raad gee?).

4:6: "hína máthete" (om julle te leer).

4:15: "paidagogoès" (leermeesters).

4:17: "kathos pantachoê ... didásko" (waarin ek ook oral ... onderrig geel.

Die begrippe wat almal op een of ander wyse verband hou met kennis, leer of onderrig, figureer so sterk in die gedagtegang van die gedeelte dat ' $\mathrm{n}$ duidelike onderriglyn beslis merkbaar is in 1 Kor. 1-4.

\subsubsection{Erkende onderrigtegnieke}

Sekere strategieë wat Paulus in 1 Kor. 1-4 aanwend om die illokusie van sy boodskap duidelik by sy lesers in Korinte tuis te bring, sluit aan by erkende onderrigtegnieke en -metodes wat daagliks in onderrigsituasies gebruik word. ${ }^{17}$ )

Enkele van die tegnieke is:

Herhaling as indriltegniek, byvoorbeeld:

die begrip "wysheid" (29 maal).

die "dwaasheid" daarteenoor (10 maal).

die "verdee/dheid" (3 maal in 1:10).

die "wêreldse" gesindheid (6 maal in 3:1-4). ${ }^{18}$ )

Verkryging van die lesers se samewerking

met behulp van onder andere:

- die inklusiewe ons, byvoorbeeld

2:10: "hemîn dè apekálupsen ho theơs" (Aan ons dan het God dit bekend gemaak), en

2:16: "hemeîs dề noền Christoê échomen" (Maar ons, ons het die Gees van Christus). ${ }^{19)}$ 
Persoonlik-gerigte metafore, byvoorbeeld:

3:9: "theoê oikodome este" (Julle is die gebou van God), en

3:16: "hơti naós theoê este" (dat julle die tempel van God is).

Vereenvoudiging

- deur middel van bekende bee/de, byvoorbeeld:

- saailand $(3: 6-9)$

- gebou $(3: 9-15)$

- tempel (3:16-17)

- regstelsel $(4: 3-5)$

- Griekse arena (4:9)

- onderwysstelsel (4:15 en 21)

- opvoeding van kinders $(3: 1-3$ en $\left.4: 14-16){ }^{20}\right)$

Vergelykings, byvoorbeeld:

3:1: "hos nep/ois" (soos met kindertjies).

Verduidelikings

Aanhalings uit die Ou Testament, byvoorbeeld:

1:19: "apofo ten sofian ton sofon, kai ten sûnesin ton suneton atheteso". (Jes. 29:14 - Die wysheid van die wyses sal Ek vernietig en die geleerdheid van die geleerdes sal Ek tot niet maak). ${ }^{21}$

Motivering van vorige stellings, byvoorbeeld:

1:17 "oe gàr apésteilén me Christós baptizein" (want Christus het my nie gestuur om te doop nie).

Voorbee/de, byvoorbeeld:

4:6 "taûta dé, adelfoí, meteschèmátisa eis emautön kai Apollon di" humás, hína en hemîn máthete". (In hierdie uiteensetting, broers, het ek myself en Apollos as voorbeelde gebruik om julle te leer).

Verskillende vraagnorme, byvoorbeeld:

1:13 "meméristai ho Christós? me Paûlos estaurothe hupèr humon, 
è eis to ónoma Paúloe ebaptisthete?" (Is Christus dan in stukke verdeel? Is Paulus miskien vir julle gekruisig, of is julle in die naam van Paulus gedoop?). ${ }^{22)}$

Ruimte vir ' $n$ volledige bespreking van elke strategie soos deur Paulus in $1 \mathrm{Kor} .1-4$ aangewend, is daar nie. Ons volstaan dan met die noem van hierdie enkele onderrigtegnieke ter motivering van ' $n$ onderriggesprek in die gekose teksgedeelte.

\section{Samevatting}

Paulus moet verseker dat die illokusie (seggingskrag) van sy taaluitinge, wat die inhoud van sy totale bediening dra, deur sy lesers in Korinte reg geinterpreteer word.

Hy beoog 'n bepaalde werklike perlokusie (werklike reaksie) op sy taaluitinge. ${ }^{23)}$ Die Korintiërs moet voortaan in hulle daaglikse lewenswandel toón dat hulle sy boodskap reg verstaan het, deur byvoorbeeld eensgesind onder mekaar te lewe, nederig te wees, die apostels te erken as dienaars van Christus, ens.

Om dit te bereik, besluit Paulus om nie sy lesers skerp te vermaan of tereg te wys nie. Inteendeel: hy kies vir onderrig as makrostrategie waardeur hy die jong gemeente van Korinte met 'n tipies herderlike onderriggesprek wil laat groei tot geestelik volwasse lidmate van Christus se kerk.

\section{Notas}

1. Vgl. A.B. du Toit, "Algemene inleiding tot die evangelies", in: HNT N, Pretoria 1979,3 vir sy onderskeiding tussen "egte briewe" en "epistels of skynbriewe".

2. J.H. Roberts, "Inleiding tot die studie van die Nuwe Testament", in: HNT 1, Pretoria 1977, 40.

3. J.L. Austin het sy reeks lesings reeds in 1955 by Harvard gelewer, maar dit is eers in 1962 postuum onder redaksie van J.O. Urmson gepubliseer: How to do things with words, London 1962.

4. G.J. Van Jaarsveld, Semantiek, Pretoria-Kaapstad 1985, 82.

5. M.C.J. van Rensburg, "Inleiding. Met wat?", in: G.J. van Jaarsveld (red.), Wat sê iy? Studies oor taalhandelinge in Afrikaans, Johannesburg 1982, xxviii.

6. H.P. van Coller en M.C.J. van Rensburg, "Appêlfunksies van literère werke", in: C. Malan (red.), Letterkunde en leser. 'n Inleiding tot lesersgerigte literêre ondersoeke, Durban 1984, 100.

7. L.M. van der Riet, Reë/s vir gesprekstrategieë in Afrikaans, Bloemfontein 1984, 8.

8. Van der Riet, a.w., 10.

9. $\quad \mathrm{g} \mathrm{l}$. hiervoor veral $\mathrm{L}$. Morris, The first epistle of Paul to the Corinthians, TNTC, Leicester 1983, 20-4 en B.C. Lategan, "1 Korinthiërs", in: HNTV, Pretoria, 62-3.

10. Vgl. Morris, a.w., 25. 
11. Lategan, a.w., 65.

12. Morris, a.w., 17.

13. Vgl. Van Rensburg, a.w., xxiv $-v$ vir'n meer volledige uiteensetting.

14. Die volgende werke huldig dié mening: F.W. Grosheide, De eerste brief aan de Kerk te Korinthe, CNT, Kampen 1957, 45; E.P. Groenewald, Die eerste brief aan die Korinthiërs, Kaapstad-Pretoria s.j., 25 en P.A. van Stempvoort, Eenheid en schisma, Nijkerk 1950, 205.

15. Die volgende woordeboeke is vir hierdie doeleinde geraadpleeg: W. Bauer, A GreekEnglish Lexicon of the New Testament and other Early Christian literature. Vertaal en hersien deur W.F. Arndt en F.W. Gingrich. 2e hersiene uitgawe deur F.W. Gingrich en F.W. Danker, Chicago ${ }^{2} 1979$; B.M. Newman. A concise Greek-English dictionary of the New Testament, London 1971; G. Abbott-Smith, A manual Greek Lexicon of the New Testament, Edinburgh 1977 en H.K. Moulton, The Analytical Greek Lexicon, London 1977.

16. Groenewald, a.w., 14.

17. Vgl. vir die onderrigtegnieke die volgende standaardwerke in Didaktiese Peda. gogiek: N.T. van Loggerenberg en A.J.C. Jooste, Verantwoordelike Opvoeding, Bloemfontein 1966; F. van der Stoep en W.J. Louw, In/eiding tot die Didaktiese Pedagogiek, Pretoria-Kaapstad 1979; P.A. Duminy en W.F. Söhnge, Didaktiek: Teorie en Praktyk, Kaapstad 1981; C.P. van der Westhuizen en C.A. Taylor, Die onderrig van die begaafde kind, Durbanville 1983 en J. Cawood, A.H. Strydom en N.T. van Loggerenberg, Doeftreffende Onderrig, Bloemfontein 1980.

18. Vgl. Duminy en Söhnge, a.w., 126 vir die funksionering van herhaling as indriltegniek.

19. Vgl. F.A. Ponelis, Afrikaanse Sintaksis, Pretoria 1979, 57 vir meer besonderhede oor die "inklusiewe ons".

20. Vgl. Van Loggerenberg en Jooste, a.w., 213 vir die onderwysbeginsels wat geld by die gebruik van beelde.

21. Vgl. Van der Stoep en Louw, a.w., 94.

22. Vgl. A.H. Snyman, "Vrae, Vraagstellings en Vraagappélle in die Nuwe Afrikaanse Vertaling van 1 Korinthiërs", in: Kongresreferate LVSA, Bloemfontein 1983, $321-334$.

23. H.P. van Coller en G.J. van Jaarsveld, "Inleiding", in Woorde as Dade: Taalhandelinge en Letterkunde, Durban-Pretoria 1984 is die eerste outeurs wat eksplisiet onderskei tussen "bedoelde" en "werklike perlokusie". 